\title{
Relation between Lipid Profile and Total Antioxidant Status among Normal Population
}

\author{
N. Gupta , P. Khadka, S. Yadav \\ Department of Biochemistry, Universal Science College, Pokhara University, Kathmandu, Nepal \\ e-mail:niraj_gupta35@yahoo.com
}

\begin{abstract}
This study was conducted to assess serum lipids in normal people in relation with their total antioxidant status. Altogether 50 fasting blood samples were collected for study in age between 20-50 years. Fasting lipid profile was determined with enzymatic method i.e. triglyceride (TG), high density lipo-protein $(H D L)$ and low density lipo-protein $(L D L)$ whereas total cholesterol (TC) by chemical method using $\mathrm{FeCl}_{3}$ reagent. The antioxidant status was determined by Ferric Reducing Ability of Plasma (FRAP) assay using TPTZ solution. The statistical analysis was done by SPSS program using Pearson's correlation coefficient. TG showed negative significant correlation with total antioxidant status $(p<0.01)$ and $H D L$ showed positive significant correlation ( $p<0.05)$. Whereas TC and LDL showed non-significant correlation with total antioxidant status ( $p>0.05)$.
\end{abstract}

Keywords : Antioxidant, Lipid Profile, Statistical Analysis, TG, HDL, LDL, TC

\section{Introduction}

Although oxidation reactions are crucial for life, they can also be damaging. Oxidation reactions produce free radicals which start chain reaction that damage the cells. To prevent the free radical damage, the body has a defense system of antioxidants. Antioxidants are a broad group of compounds that destroy single oxygen molecules, also called free radicals thereby protecting against oxidative damage. Antioxidants terminate these chain reactions by removing the free radical intermediate and inhibit the other oxidation reactions. The total antioxidant status has significant relation with lipid profile. Experimental studies have demonstrated that oxidation of LDL plays an important role in the development and progression of atherosclerosis in animal models ${ }^{1-3}$. Observational epidemiological studies have also documented an inverse association between increased intake of antioxidant vitamins such as vitamin $\mathrm{E}$, B-carotene, and vitamin $\mathrm{C}$ and reduced morbidity and mortality rates from coronary heart disease. Increased oxidative stress and the generation of the free oxygen radicals can result in modification of LDL to oxidized LDL that could lead to atherosclerotic lesions ${ }^{4}$.

The modern concept of medicine envisages that a subtle balance of redox homeostasis is necessary to maintain normal health and to avoid disease and that in this redox homeostasis free radicals and antioxidants play a crucial role, in many diseases especially age related ones. To

\section{* Corresponding author}


our knowledge, no work has so far been done in this regard on Nepali population and relationship, if any, with Body Mass Index (BMI) and Weight/Height (W/H) ratio, which are currently used as anthropometric markers for measuring overweight and obesity except some studies published from laboratory ${ }^{8}$. This study addresses relation of antioxidant status with lipid profile in normal population of different age groups. A lipid profile is possible because of the activity of lipids in the bloodstream. Essentially, lipids will adhere to proteins found in the system, creating what is known as lipoproteins. The lipid profile test helps to not only identify the total lipoprotein content in the blood, but also breaks down the components of the lipids in order to determine how much of each element is present.

Free radicals and antioxidants are considered so vital to our understanding of the origin of cancer, aging, illness, and disease that they have become a profound area of research. An important concern to human today is environmental hazards and its adverse effect to the health. The excess production of reactive oxygen species may initiate lipid peroxidation in cell membrane. These processes may result in a loss of contractile function of the heart and lead to severe myocardial cell damage, collectively termed as reperfusion injury ${ }^{5}$. The significant decrease in endogenous antioxidant in the patients could be due to overwhelming production and accumulation of superoxide anion causing inhibition of antioxidant activity. Whatever might be the cause of the decreased endogenous antioxidants, the net result is accumulation of $\mathrm{H}_{2} \mathrm{O}_{2}$, one of the most damaging products of the free radical metabolism. $\mathrm{H}_{2} \mathrm{O}_{2}$ can readily react with superoxide anion to produce the highly toxic hydroxyl radical and $\mathrm{HOCl}$. Many findings suggest that antioxidants depletion has relevant impact to the precipitation of myocardial infarction and these findings are consistent with the notion that increased levels of antioxidants are protective ${ }^{6}$.

$$
\begin{aligned}
& \mathrm{O}_{2} \text { (molecular oxygen) } \stackrel{\mathrm{e}}{\longrightarrow} \mathrm{O}_{2}^{-} \text {(Superoxide anion radical) } \stackrel{\mathrm{e}-, \mathrm{H}+}{\longrightarrow} \mathrm{H}_{2} \mathrm{O}_{2} \text { (Hydrogen peroxide) } \\
& \mathrm{H}_{2} \mathrm{O}_{2} \text { (Water) }
\end{aligned}
$$

Free radicals can be divided into 2 species: - ROS (Reactive Oxygen Species) and RNS (Reactive Nitrogen Species). ROS include superoxide $\left(\cdot \mathrm{O}_{2}^{-}\right)$and its protonated form hydroperoxyl $\left(\mathrm{HO}_{2} \cdot\right)$, hydroxyl $(\cdot \mathrm{OH})$, peroxyl $\left(\mathrm{HO}_{2}{ }^{-}\right)$, alkoxy $(\mathrm{RO} \cdot)$ and non-radicals: hydrogen peroxide $\left(\mathrm{H}_{2} \mathrm{O}_{2}\right)$, hypochlorous acid $(\mathrm{HOCl})$, ozone $\left(\mathrm{O}_{3}\right)$ and singlet oxygen $\left(\mathrm{O}_{2}\right)$ that are agent or are readily converted to free radicals. Whereas, RNS includes nitric oxide $\left(\mathrm{NO}^{-}\right)$, peroxynitrite $\left(\mathrm{ONOO}^{-}\right)$and peroxynitrous acid $(\mathrm{ONOOH})$.

Molecular oxygen can be reduced to water. The intermediate step of oxygen reduction are the formation of the superoxide anion radical, hydrogen peroxide and hydroxyl radical by the addition of one, two and three electrons respectively ${ }^{7}$.

RNS are produced with the reaction of nitric oxide with superoxide $\left(\mathrm{O}_{2}\right)$ to form peroxynitrite(ONOO). 
$\cdot \mathrm{NO}$ (nitric oxide) $+\mathrm{O}_{2} \cdot($ superoxide $) \rightarrow \mathrm{ONOO}$ (peroxy nitrite)

Additionally, peroxynitrite able to react with other molecules to form additional types of RNS including peroxynitrous acid, nitrogen dioxide $\left(\cdot \mathrm{NO}_{2}\right)$ and dinitrogen trioxide $\left(\mathrm{N}_{2} \mathrm{O}_{3}\right)$ as well as other types of chemically reactive free radicals.

$$
\begin{aligned}
& \mathrm{ONOO}+\mathrm{H}^{+} \rightarrow \text { (peroxynitrous) } \rightarrow \cdot \mathrm{NO}_{2}+\cdot \mathrm{OH} \\
& \mathrm{ONOO}^{-}+\mathrm{CO}_{2} \rightarrow \mathrm{ONOOCO}_{2} \text { (nitrous peroxycarbonate } \\
& \mathrm{ONOOCO}_{2}^{-} \rightarrow \cdot \mathrm{NO}_{2}+\mathrm{O}=\mathrm{C}(\mathrm{CO} \cdot \text { ) }
\end{aligned}
$$

\section{Experimental Methods}

Fasting venous blood samples were collected from different places of Kathmandu valley (50 samples from normal people) aseptically by vein puncture into clean and dry glass vials. The blood was allowed to clot. Then sample was centrifuged at $3000 \mathrm{rpm}$ for $5 \mathrm{~min}$ and serum was collected for analysis. Total Cholesterol was estimated using chemical method (ZAK's method) ${ }^{9}$ whereas TG,and HDL-cholesterol was estimated using the enzymatic kit method (GPO/PAP method ${ }^{10,15.16}$ and PEG precipitation method ${ }^{10,11,12,13,14}$ respectively) while LDL was estimated by using Friedewald's formula ${ }^{10,11,12,13,14}$.

$$
\mathrm{LDL}=(\mathrm{TC})-(\mathrm{TG} / 5)-(\text { HDL cholesterol })
$$

\section{Analysis of total cholesterol (by ZAK's method)}

$\mathrm{FeCl}_{3}$ solution $(0.05 \% \mathrm{w} / \mathrm{v})$ was prepared in acetic acid. 3 dry and clean tubes were taken and labeled as Blank (B), Test (T) and Standard(S). $10 \mathrm{ml}$ of ferric chloride reagent and $0.1 \mathrm{ml}$ of serum sample was added in the test labeled tube. It was then mixed well, incubated at room temperature for $10 \mathrm{~min}$ and centrifuged at $2500-3000 \mathrm{rpm}$ for 5 minutes to obtain clear supernatant. $5 \mathrm{ml}$ of supernatant was then taken in another test labeled tube and $5 \mathrm{ml}$ of cholesterol standard and $\mathrm{FeCl}_{3}$ reagent was added in standard and blank respectively. $3 \mathrm{ml}$ of conc. $\mathrm{H}_{2} \mathrm{SO}_{4}(18.38 \mathrm{M}, 96 \%$ pure $)$ was then added in each tube and was mixed and incubated at room temperature for 30 mins. Absorbance was then taken at $560 \mathrm{~nm}$ by Digital Photo colorimeter (model no. 312) and calculation was done.

\section{Analysis of HDL (PEG Precipitation method)}

$200 \mu \mathrm{l}$ sample and $200 \mu \mathrm{l}$ precipitating reagent was taken into the clean and dry tubes. They were mixed well and incubated at room temperature for $5 \mathrm{~min}$ and centrifuged at 2500-3000 rpm for 5 minutes to obtain clear supernatant. Supernatant was pipetted and kept into clean and dry tube and leveled as Blank (B), Standard (S), and Test (T) and one $\mathrm{ml}$ of working reagent was added to each tube. Similarly $50 \mu \mathrm{l}$ of supernatant was added to sample tubes, $50 \mu \mathrm{l}$ of $\mathrm{D} / \mathrm{W}$ to blank tube and HDL standard cholesterol to standard tube. Mixed well and incubated at $37^{\circ} \mathrm{C}$ for 5 
min Absorbance was measured at $505 \mathrm{~nm}$ by Digital Photo colorimeter and then calculation was done.

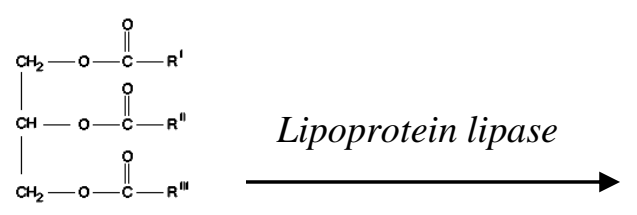

Triglycerides

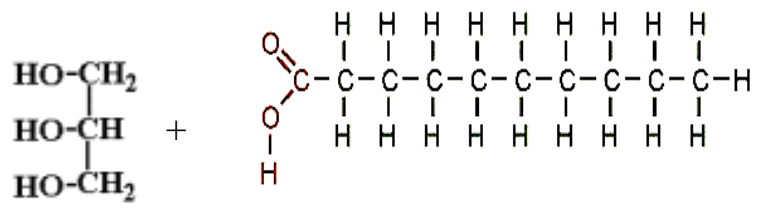

Glycerol

free fatty acids

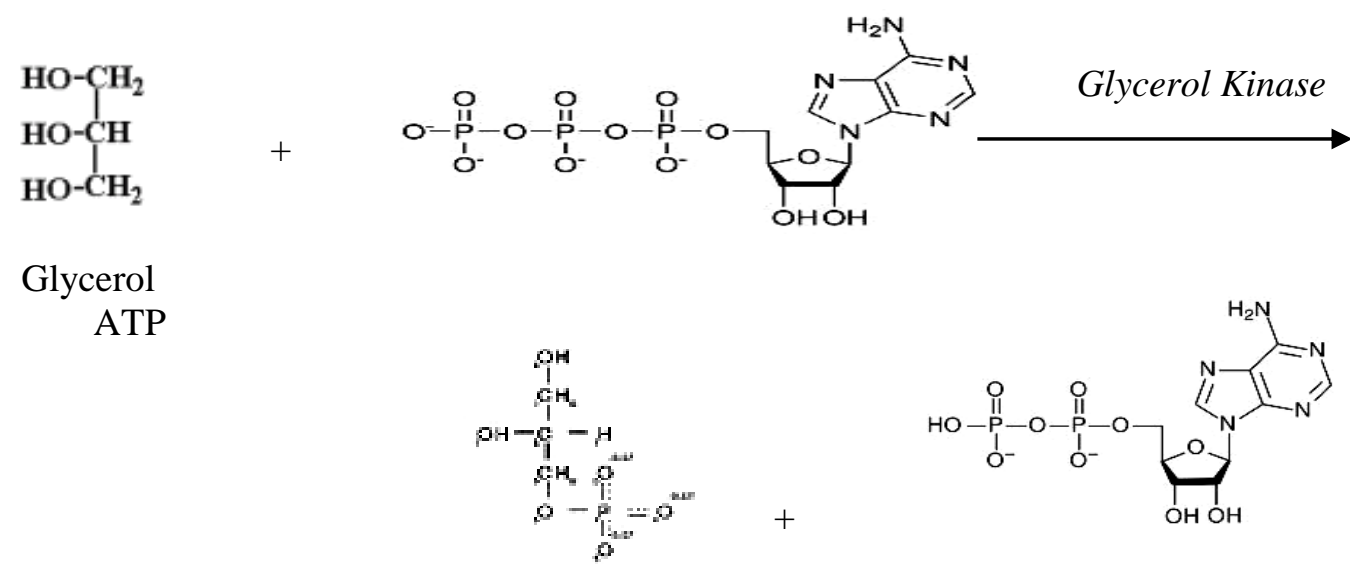

Glycerol 3-phosphate

ADP

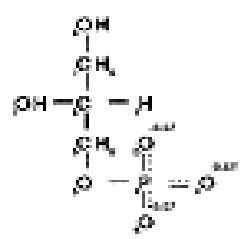

Glycerol 3-phosphate

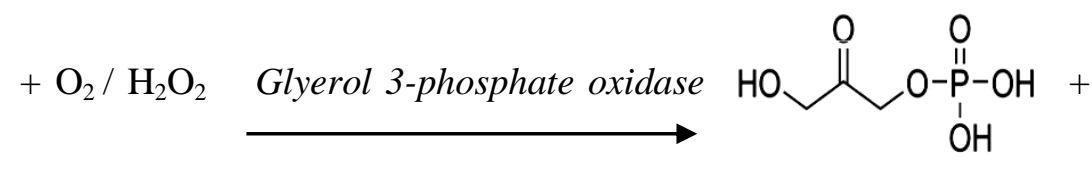

Dihydroxyacetone phosphate
$\mathrm{H}_{2} \mathrm{O}_{2}+4$-aminoantipyrine $+\overbrace{\text { Phenol }}^{\mathrm{OH}} \underset{\text { Peroxidase }}{\longrightarrow}$

Quinonimine Dye (Red) 


\section{Analysis of Triglyceride (GPO/PAP method)}

Clean dry tubes were taken and $1 \mathrm{ml}$ of working reagent was added to each tube labeled as Blank (B), Test (T) and Standard (S). 10 $\mu 1$ of D/W, 10 $\mu 1$ of sample and $10 \mu \mathrm{l}$ of standard TG was added simultaneously. Mixed well and was incubated at $37^{\circ} \mathrm{C}$ for $5 \mathrm{~min}$. Absorbance was made at $505 \mathrm{~nm}$ with Digital Photo colorimeter and calculation was done Lipoprotein lipase hydrolyses triglyceride to glycerol and free fatty acids. The glycerol formed interacts with ATP in the presence of glycerol kinase forming glycerol 3-phosphate which is oxidized by glycerol phosphate oxidase to form hydrogen peroxide. Finally $\mathrm{H}_{2} \mathrm{O}_{2}$ further reacts with phenolic compound and 4-aminoantipyrine by the catalytic action of peroxidase to form a red-coloured quinoneimine dye complex. Intensity of the colour formed is directly proportional to the amount of TG present in the sample.

Similarly total antioxidant assay was estimated in blood serum using Ferric Reducing Ability of Plasma (FRAP) assay ${ }^{7}$. The FRAP reagent was used for the estimation of total antioxidant status. $300 \mathrm{mM}$ acetate buffer was prepared by dissolving $0.82 \mathrm{~g}$ sodium acetate in $8.11 \mathrm{ml}$ glacial acetic acid and the volume was made $500 \mathrm{ml}$ by adding distilled water. $10 \mathrm{~mm}$ TPTZ solution was prepared by mixing $0.031 \mathrm{~g}$ TPTZ in $10 \mathrm{ml} 40 \mathrm{mM} \mathrm{HCl}$ solution and dissolving it at $50{ }^{\circ} \mathrm{C}$ in water bath. Similarly, $20 \mathrm{mM} \mathrm{FeCl}_{3}$ was prepared by dissolving $0.032 \mathrm{~g}$ $\mathrm{FeCl}_{3}$ in $10 \mathrm{ml}$ distilled water.

The working FRAP reagent was then prepared by mixing $300 \mathrm{mM}$ acetate buffer, $\mathrm{pH}=3.6$, $10 \mathrm{~mm}$ TPTZ solution and $20 \mathrm{mM} \mathrm{FeCl}_{3}$ in the ratio of 10:1:1 at the time of use. The standard used was $100 \mu \mathrm{mol} / \mathrm{L} \mathrm{FeSO}_{4} .7 \mathrm{H}_{2} \mathrm{O}$. The colorimeter was then set at zero by the blank i.e. $3 \mathrm{ml}$ of FRAP reagent. $10 \mu \mathrm{l}$ sample was mixed with $3 \mathrm{ml}$ of working FRAP reagent. Then after, samples were allowed to stand for 4 min and absorbance was taken at $620 \mathrm{~nm}$. This process was repeated thrice for single sample.

Calculation:

Data were analyzed statistically by Pearson's Correlation coefficient using SPSS software.

Frap Value of Sample $(\mu \mathrm{mol} / \mathrm{L})$ $=\frac{\text { mean of absorbance of sample at } 4 \mathrm{~min} * \text { concentration of standard }}{\text { mean of absorbance of Standard at } 4 \mathrm{~min}}$

\section{Results and Discussion}

\section{Correlation between TC and antioxidant status}

TC was determined using ZAK's method and total antioxidant was determined by FRAP assay method. The two parameters were then statistically analyzed by Pearson's correlation coefficient using SPSS software and are tabulated in Table 1.

The statistical analysis showed no correlation between TC and antioxidant status among normal population in the table 1 i.e. $p>0.05$ significant value. 
Table 1: Statistical analysis between TC and antioxidant status

\begin{tabular}{|c|c|c|c|}
\hline & & $\mathrm{TC}$ & Antioxidant \\
\hline \multirow[t]{3}{*}{$\mathrm{TC}$} & Pearson Correlation & 1 & 0.085 \\
\hline & Sig. (2-tailed) & & 0.557 \\
\hline & $\mathrm{N}$ & 50 & 50 \\
\hline \multirow[t]{3}{*}{ Antioxidant } & Pearson Correlation & 0.085 & 1 \\
\hline & Sig. (2-tailed) & 0.557 & \\
\hline & $\mathrm{N}$ & 50 & 50 \\
\hline
\end{tabular}

\section{Correlation between $T G$ and antioxidant status:}

TG was determined using enzymatic kit method and total antioxidant was determined by FRAP assay method. The two parameters were then statistically analyzed by Pearson's correlation coefficient using SPSS software. The result is summarized in table 2.

Table 2: Statistical analysis between TG and antioxidant status

\begin{tabular}{|l|l|c|c|}
\hline & & Antioxidant & TG \\
\hline \multirow{3}{*}{ Antioxidant } & Pearson Correlation & 1 & $-0.378^{* *}$ \\
\cline { 2 - 4 } & Sig. (2-tailed) & & 0.007 \\
\cline { 2 - 4 } & $\mathrm{N}$ & 50 & 50 \\
\hline \multirow{2}{*}{ TG } & Pearson Correlation & $-0.378^{* *}$ & 1 \\
\cline { 2 - 4 } & Sig. (2-tailed) & 0.007 & 50 \\
\hline \multicolumn{2}{|l|}{} \\
\hline \multirow{2}{*}{ **. Correlation is significant at the 0.01 level (2-tailed) } & 50 & \\
\hline
\end{tabular}

The statistical analysis showed negative significant correlation between TG and antioxidant status among normal population in the table 2 i. e. $p<0.01$ significant value. The statistical analysis shows that higher the level of TG, lower the antioxidant level and vice versa.

Correlation between HDL and antioxidant status:

Total HDL was determined by using PEG precipitation method and total antioxidant was determined by FRAP assay method. The two parameters were then statistically analyzed by Pearson's correlation coefficient using SPSS software.

Table 3: Statistical analysis between HDL and antioxidant

\begin{tabular}{|l|l|c|c|}
\hline & & Antioxidant & HDL \\
\hline \multirow{4}{*}{ Antioxidant } & Pearson Correlation & 1 & $0.310^{*}$ \\
\cline { 2 - 4 } & Sig. (2-tailed) & & 0.028 \\
\cline { 2 - 4 } & $\mathrm{N}$ & 50 & 50 \\
\hline \multirow{3}{*}{ HDL } & Pearson Correlation & $0.310 *$ & 1 \\
\cline { 2 - 4 } & Sig. (2-tailed) & 0.028 & \\
\cline { 2 - 4 } & $\mathrm{N}$ & 50 & 50 \\
\hline \multirow{2}{*}{ *. Correlation is significant at the 0.05 level (2-tailed). } \\
\hline
\end{tabular}

The statistical analysis showed positive significant correlation between HDL and antioxidant status among normal population in the table 3 i.e. $p<0.05$ significant value. The statistical analysis shows that as the level of TG increases, the level of antioxidant also increases. 


\section{Correlation between LDL and antioxidant status}

LDL was calculated by Friedewald's formula and total antioxidant was determined by FRAP assay method. The two parameters were then statistically analyzed by Pearson's correlation coefficient using SPSS software.

Table 4: Statistical analysis between LDL and antioxidant

\begin{tabular}{|l|l|c|c|}
\hline & & Antioxidant & LDL \\
\hline Antioxidant & $\begin{array}{l}\text { Pearson } \\
\text { Correlation }\end{array}$ & 1 & 0.234 \\
\hline \multirow{3}{*}{ LDL } & Sig. (2-tailed) & & 0.103 \\
\cline { 2 - 4 } & N & 50 & 50 \\
\hline & $\begin{array}{l}\text { Pearson } \\
\text { Correlation }\end{array}$ & 0.234 & 1 \\
\cline { 2 - 4 } & Sig. (2-tailed) & 0.103 & \\
\cline { 2 - 4 } & N & 50 & 50 \\
\hline
\end{tabular}

The statistical analysis showed that there is no correlation between LDL and antioxidant status among normal population in the table 4 i. e. $p>0.05$ significant value.

\section{Conclusion}

The statistical analysis shows that there is significant correlation of TG and HDL with antioxidant status. TG and antioxidant status are indirectly proportional and HDL and antioxidant are directly proportional to each other. The elevated level of antioxidant is important to body as people grow older because it prevent from age related diseases. The higher the level of antioxidant inhibits oxidation of lipid which may cause coronary heart disease and also arthrosclerosis. The statistical analysis of LDL and antioxidant showed no correlation between them but literature review says significant relation between LDL and antioxidant. The increased intake of antioxidants reduces the oxidation of LDL that could lead to atherosclerotic lesions.

\section{Acknowledgement}

The authors would like to express their sincere gratitude to Mr. Ranjit Thakur, Ms. Shweta Khanal and Ms. Indu Singh for providing study materials. We would like to thank Mr. Amit Bhagat for his technical skills.

\section{References:}

1. Diaz MN, Frei B, Vita JA, Keaney JF Jr. Antioxidants and atherosclerotic heart disease. N Engl J Med. 1997; 337: 408-416.

2. Tribble DL. AHA Science Advisory. Antioxidant consumption and risk of coronary heart disease: emphasis on vitamin C, vitamin $\mathrm{E}$, and beta-carotene: a statement for healthcare professionals from the American Heart Association. Circulation. 1999; 99: 591-595. 
3. Spencer AP. Carson DS. Crouch MA. Vitamin E and coronary artery disease. Arch Intern Med. 1999; 159: 1313-1320.

4. Patil N,Chavan B,Karnik N.D Antioxidant status in patients with acute myocardial infraction Indian Journal of Clinical Biochemistry, 2007 / 22 (1) 45-51.

5. Jacobson, M. D., Reactive oxygen species and programmed cell death. Trends Biochem. Sci., 1996, 243, 81-119.

6. Tomoda, H. et al., SOD activity as a predictor of myocardial reperfusion and salvage in acute myocardial infarction. Am. Heart J., 1996, 131, 849-856.

7. Khanal S., Singh I. and Thakur R.. Total antioxidant content of foods, beverages, spices, herbs and supplement used in Nepal (2010) submitted to Universal Science College, Pokhara University, Department of Biochemistry in partial fulfillment of the requirement for degree of B. Sc. In Biochemistry.

8. Maharjan BR, Jha JC, Adhikari D, Vishwanath P, Baxi J, Alurkar VM and Singh PP. A study of oxidative stress, antioxidant status and lipid profile in diabetic patient in the western region of Nepal. Kathmandu University Medical Journal (2008), Vol. 6, No. 1, Issue 21, 16-22.

9. TG Morrs. A comparision of methods for the estimation of serum cholesterol and values in random samples of population in the 55-64 age group, Journal of Clinical pathology (1959), 12, 518.

10. Trinder, P., (1969) Ann. Clin. Biochem. 6: 24.

11. Allain, C. C., et al, (1974) Clin. Chem.20: 470.

12. Flegg, H. M., (1972) Ann. Clin. Biochem. $10: 79$.

13. Grillo, F., et al, (1981) Clin. Chem. $27: 375$.

14. Demacker, P. N. M., et al, (1980) Clin. Chem. $26: 1775$.

15. Bucolo, G., David, H., (1973) Clin. Chem. 19:476.

16. Fossati, P., Prencipe, L., (1982) Clin. Chem. 28:2077. 